\title{
Morphological Characteristics, Classifications and Difficulties in the Use of Diagnostic Criteria for Serrated Lesions of the Large Intestine
}

\author{
Cesar de Souza Bastos Junior ${ }^{1 \oplus}$ Vera Lucia Nunes Pannain ${ }^{10} \quad$ Adriana Caroli-Bottino ${ }^{1 \odot}$ \\ ${ }^{1}$ Departamento de Anatomia Patológica, Universidade Federal do Rio \\ de Janeiro, Rio de Janeiro, RJ, Brazil \\ Address for correspondence Cesar de Souza Bastos Junior, MSC, \\ Universidade Federal do Rio de Janeiro, Rua Aroazes 71/303, \\ Jacarepaguá, Rio de Janeiro, RJ, 22775-060, Brazil \\ J Coloproctol 2021;41(4):430-437. \\ (e-mail: cesar.548@gmail.com).
}

\begin{abstract}
Keywords

- Sessile serrated lesion

- serrated lesions

- serrated adenoma

- interobserver concordance

- reproducibility
\end{abstract}

Introduction Colorectal carcinoma (CRC) is the most common gastrointestinal neoplasm in the world, accounting for $15 \%$ of cancer-related deaths. This condition is related to different molecular pathways, among them the recently described serrated pathway, whose characteristic entities, serrated lesions, have undergone important changes in their names and diagnostic criteria in the past thirty years. The multiplicity of denominations and criteria over the last years may be responsible for the low interobserver concordance (IOC) described in the literature.

Objectives The present study aims to describe the evolution in classification of serrated lesions, based on the last three publications of the World Health Organization (WHO) and the reproducibility of these criteria by pathologists, based on the evaluation of the IOC.

Methods A search was conducted in the PubMed, ResearchGate and Portal Capes databases, with the following terms: sessile serrated lesion; serrated lesions; serrated adenoma; interobserver concordance; and reproducibility. Articles published since 1990 were researched. Results and Discussion The classification of serrated lesions in the past thirty years showed different denominations and diagnostic criteria. The reproducibility and IOC of these criteria in the literature, based on the kappa coefficient, varied in most studies, from very poor to moderate.

Conclusions Interobserver concordance and the reproducibility of microscopic criteria may represent a limitation for the diagnosis and appropriate management of these lesions. It is necessary to investigate diagnostic tools to improve the performance of the pathologist's evaluation, for better concordance, and, consequently, adequate diagnosis and treatment.

\section{Introduction}

Colorectal carcinoma (CRC) is the most common gastrointestinal malignancy in the world, with $\sim 150,000$ new cases per year in the United States, $\sim 52,000$ deaths annually, and $15 \%$ of all cancer-related deaths. ${ }^{1}$ The development of CRC is related to a combination of molecular events that include genetic and epigenetic abnormalities, traditionally received

August 8, 2020

accepted

January 15, 2021

published online

July 19, 2021
DOI https://doi.org/

10.1055/s-0041-1730016.

ISSN 2237-9363.

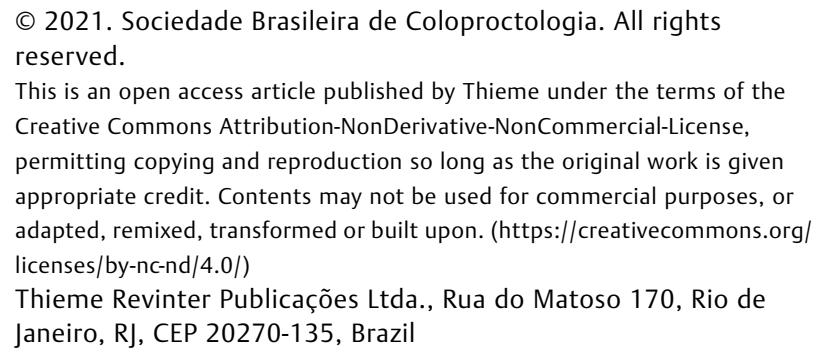

This is an open access article published by Thieme under the terms of the Creative Commons Attribution-NonDerivative-NonCommercial-License, permitting copying and reproduction so long as the original work is given appropriate credit. Contents may not be used for commercial purposes, or adapted, remixed, transformed or built upon. (https://creativecommons.org/ licenses/by-nc-nd/4.0/)

Thieme Revinter Publicações Ltda., Rua do Matoso 170, Rio de Janeiro, RJ, CEP 20270-135, Brazil 
described by two genetic pathways: the adenomatous polyposis coli (APC)/ $\beta$-catenin pathway (or classic sequence pathway - adenoma/adenocarcinoma), which corresponds to up to $80 \%$ of sporadic colon tumors, and the microsatellite instability pathway, related to the loss of the DNA mismatch repair (MMR) gene function, which corresponds to $15 \%$ to $30 \%$ of the cases. ${ }^{2-4}$ In recent decades, an alternative pathway has been described, characterized by mutations in BRAF oncogene and silencing of different groups of genes by hypermethylation of $\mathrm{CpG}$ regions, identified in cancers related to the (non-hereditary) MMR mutation. In contrast, KRAS and p53 mutations, common in the classic pathway, are not detected in these groups of tumors, showing a characteristic molecular profile of combination of microsatellite instability (MSI), BRAF mutation, and methylation of genes such as MLH1, p16 and MGMT. ${ }^{5}$ With the evolution in the knowledge on the molecular biology of these lesions, it was possible to identify that they represent a group of lesions characterized mainly by glandular serrated lumens with a specific genetic signature. These entities, with distinct molecular profiles, morphologically resemble the lesions of sessile architecture and serration of glandular lumens, described by Longacre and Fenoglio-Preiser ${ }^{6}$ in 1990, and later improved by Torlakovic and Snover ${ }^{7}$ in 1996 , and first included in World Health Organization's (WHO) Classification of Tumors, ${ }^{12}$ also known as the WHO Blue Books, in 2000. The multiple new classifications and terminologies for these lesions later created, associated with recent information about biological behavior and treatments, have been reviewed over the last decades, and grouped in the serrated pathway of carcinogenesis. ${ }^{8}$ The correlation between the different carcinogenesis pathways described so far and the molecular subtypes of CRC currently identified demand increasing investigation regarding the role of morphological and molecular profiles of serrated lesions and the serrated pathway in colorectal carcinogenesis.

\section{Objectives}

The objectives of the present article are to describe the evolution in the classification of serrated lesions, based on nomenclatures and microscopic criteria used in the last 3 WHO publications (of 2000, ${ }^{11} 2010,{ }^{3}$ and $2019^{9}$ ), and to describe the reproducibility of these criteria and the pathologists' ability to make a diagnosis, over the last years, based on the intrerobserver concordance (IOC) by the kappa coefficient, according to different articles published in the literature.

\section{Methods}

A systematic review of articles was performed in the PubMed, ResearchGate and Portal Capes databases, using the following terms: sessile serrated lesion; serrated lesions; serrated adenoma; interobserver concordance; and reprodutibility. A total of 30 articles published between January 1990 and June 2020 were selected.

\section{Results and Discussion}

According to the 2019 WHO classification, intestinal serrated lesions are classified as hyperplastic polyps (HPs), serrated lesions with and without dysplasia, traditional serrated adenomas (TSAs), and unclassified serrated adenomas. ${ }^{9}$ The nomenclature of these lesions in classifications and diagnostic criteria has undergone changes in the last three decades and, and, in order to better understand taht, it is necessary to review the definitions adopted in the first published studies. In 1990, Longacre and Fenoglio-Preiser ${ }^{6}$ described some polyps of serrated architecture that presented characteristics common to conventional adenomas (CAs) and HPs, and named them as mixed hyperplastic/adenomatous polyps - serrated adenomas. In 1996, Torlakovic and Snover ${ }^{7}$ described a group of serrated lesions, in a case of serrated polyposis syndrome (SPS), which showed abnormal architecture and cytological dysplasia, defined as "sessile serrated adenomas (SSAs)," currently considered precursor lesions for CRC with MSI. ${ }^{8}$ The prevalence of SSAs was underestimated for years, corresponding from $0.1 \%$ to $14.7 \%$ of all colorectal polyps. The differentiation of these from other conventional polyps and adenomas became fundamental, since the identification of a morphological and molecular profile related to the serrated carcinogenesis pathway was described, with different prognosis, follow-up and response to treatment when compared to traditional CRCs. ${ }^{9-11}$ For the first time in 2000, the $\mathrm{WHO}^{12}$ described two main types of serrated lesions: HPs (metaplastic) and serrated adenomas, as well as mixed hyperplastic/adenomatous polyps. In 2010 , the $\mathrm{WHO}^{3}$ classified serrated lesions into three main categories: 1) HPs, microvesicular HPs (MVHPs), goblet cell-rich HPs (GCRHPs) and mucin-poor HPs (MPHPs); 2) sessile serrated adenomas/polyps (SSA/Ps), with and without cytological dysplasia, conventional ( similar to conventional, non-serrated adenomas), or serrated (pencillate nuclei and eosinophilic cytoplasm); and 3) TSAs. The WHO classification also considered the diagnostic criteria of mixed polyps (MPs), which contain alterations of more than one type of serrated lesion, but which could represent collision lesions or a possible progression from one lesion to another, and recommended that the terminology should be used with caution. ${ }^{3}$ In 2019, the $\mathrm{WHO}^{9}$ published the 5 th edition of its classification: 1 ) MVHPs and GCRHPs; 2) sessile serrated lesions (SSLs), with and without cytological dysplasia (conventional and/or serrated); 3) TSAs; and 4) unclassified serrated adenomas, described as lesions with intermediate characteristics between SSLs and TSAs, in addition to "serrated tubulo-villous adenomas". The latter category apparently replaces the previous nomenclature of "mixed polyps". The denominations adopted by the 2019 WHO classification were already recommended by the 2017 British Society of Gastroenterology's ${ }^{5}$ position statement, which used the terms "hyperplastic polyp, sessile serrated lesions with and without dysplasia, traditional serrated adenoma, and mixed polyps". - Table 1 shows the main classifications of serrated lesions in the past thirty years, based on the last three WHO 
432 Use of Diagnostic Criteria for Serrated Lesions of the Large Intestine Bastos Junior et al.

Table 1 Evolution in the classification of serrated lesions

\begin{tabular}{|c|c|}
\hline Main authors and publications & Classification of serrated lesions \\
\hline Longacre and Fenoglio-Preiser $^{6}$ & $\begin{array}{ll} & \text { Hyperplastic polyp. } \\
\text { - } & \text { Mixed hyperplastic adenomatous polyp/serrated adenoma. }\end{array}$ \\
\hline Torlakovic and Snover $^{7}$ & $\begin{array}{l}\text { - Hyperplastic polyp. } \\
\text { - Sessile serrated adenoma. } \\
\text { - } \text { Mixed hyperplastic adenomatous polyp. }\end{array}$ \\
\hline World Health Organization (WHO) $2000^{12}$ & $\begin{array}{l}\text { - } \quad \text { Hyperplastic polyp (metaplastic). } \\
\text { - } \quad \text { Serrated adenoma. } \\
\text { - } \quad \text { Mixed polyp (hyperplastic/adenomatous). }\end{array}$ \\
\hline WHO $2010^{3}$ & $\begin{array}{l}\text { - Hyperplastic polyp (microvesicular, globet cell-rich and mucin-poor). } \\
\text { - } \quad \text { Sessile serrated polyp/adenoma (with or without dysplasia). } \\
\text { - } \quad \text { Traditional serrated adenoma. } \\
\text { - } \quad \text { Mixed polyp. }\end{array}$ \\
\hline WHO $2019^{9}$ & $\begin{array}{l}\text { - Hyperplastic polyp (microvesicular, globet cell-rich and mucin-poor). } \\
\text { - Sessile serrated lesion. } \\
\text { - Sessile serrated lesion with dysplasia. } \\
\text { - } \quad \text { Traditional serrated adenoma. } \\
\text { - Unclassified serrated polyp. }\end{array}$ \\
\hline
\end{tabular}

classifications and original descriptions from Longacre and Fenoglio-Preiser ${ }^{6}$ and Torlakovic and Snover. ${ }^{7}$

\section{Current Overview of Serrated Lesions}

The morphological characteristics of each serrated lesion will be addressed briefly. - Figure 1 and - Table 2 show the main histological differences between the serrated lesions.

\section{Hyperplastic Polyps}

Hyperplastic polyps are the most commonly observed type of serrated lesion, corresponding to between $24 \%$ and $42 \%$ of all intestinal polyps, and $83 \%$ to $96 \%$ of serrated lesions. $5,10,11$ They are usually small, measuring less than $5.0 \mathrm{~cm}$, and with a sessile pattern, containing glands with columnar epithelium, goblet cells, and elongated and dilated crypts. They have straight crypts that extend symmetrically from the polyp surface to the muscularis mucosa, with greater luminal distension and serration in its proximal portion, without important architectural distortion, horizontal or irregular branching pattern. ${ }^{11}$ The basal membrane may be thickened; reactive epithelial alterations and mitotic figures may be present, and should not be confused with dysplasia. ${ }^{5}$ Currently, two morphological types of HPs are recognized. The most common is the MVHP, composed of glands with epithelial cells containing mucus, apical serration and goblet cells in lower frequency; it is more often located in the left colon and rectum, although $10 \%$ to $15 \%$ of them may be located in the right and transverse colons. ${ }^{13}$ The second type, corresponding to one third of the total, the GCRHP, exhibits numerous goblet cells and lower apical serration, being more commonly found in the left colon and rectum. The MVHP most often has mutations in the BRAF gene, and the GCRHP may exhibit KRAS mutations, suggesting that they may be in different parts of the serrated pathway. A third type, rarely identified, described in previous publications, ${ }^{3,12}$ the MPHP, was excluded from the 2019 WHO classification; little is known about the molecular characteristics related to this subtype, and one theory is that it would correspond to the MVHP with reactive epithelial alterations secondary to inflammation. ${ }^{13}$

\section{Sessile Serrated Lesions}

Sessile serrated lesions and TSAs generally have in common the serrated appearance of their crypt lumens. They are larger than HPs and, most SSLs occur in the right colon. The diagnosis is based on the distorted and disorganized pattern of the crypts, mainly in the basal portion, with serration along the whole extension of the crypt, including its base, which is dilated, and with horizontal branches forming a "J," "L" or "Inverted T" pattern. Superficial biopsies may represent a greater challenge in the differentiation from MVHPs. The crypts of the SSLs tend to be arranged parallel to the muscularis mucosa and sometimes herniated through it, not necessarily representing invasion. They show clear columnar cells with a less eosinophilic cytoplasm than those observed in TSAs. The presence of mucinous cells in the base of the crypts can lead to mucus accumulation and dialtion of the luminal gland, differently from HPs, which show narrow lumens in their bases, and proliferative cells. ${ }^{4}$ Another important issue is whether SSLs arise de novo or originate from HPs, particularly MVHPs. The identification of most of pure SSLs at the right colon and MVHPs at the left colon support the de novo theory. However, the frequent identification of areas of MVHPs in large SSLs, associated with the presence of hypermethylation and BRAF mutations observed in $\sim 66 \%$ to $75 \%$ of MVHPs, and $~ 85 \%$ of SSLs, suggests that SSLs may in fact represent advanced forms of MVHPs. ${ }^{14}$ Sessile serrated lesions were defined in the $2010 \mathrm{WHO}^{3}$ classification as lesions presenting the aforementioned characteristics in at least three crypts (or two adjacent crypts). However, according to the criteria of the American Gastroenterology Association (AGA), the presence of these 


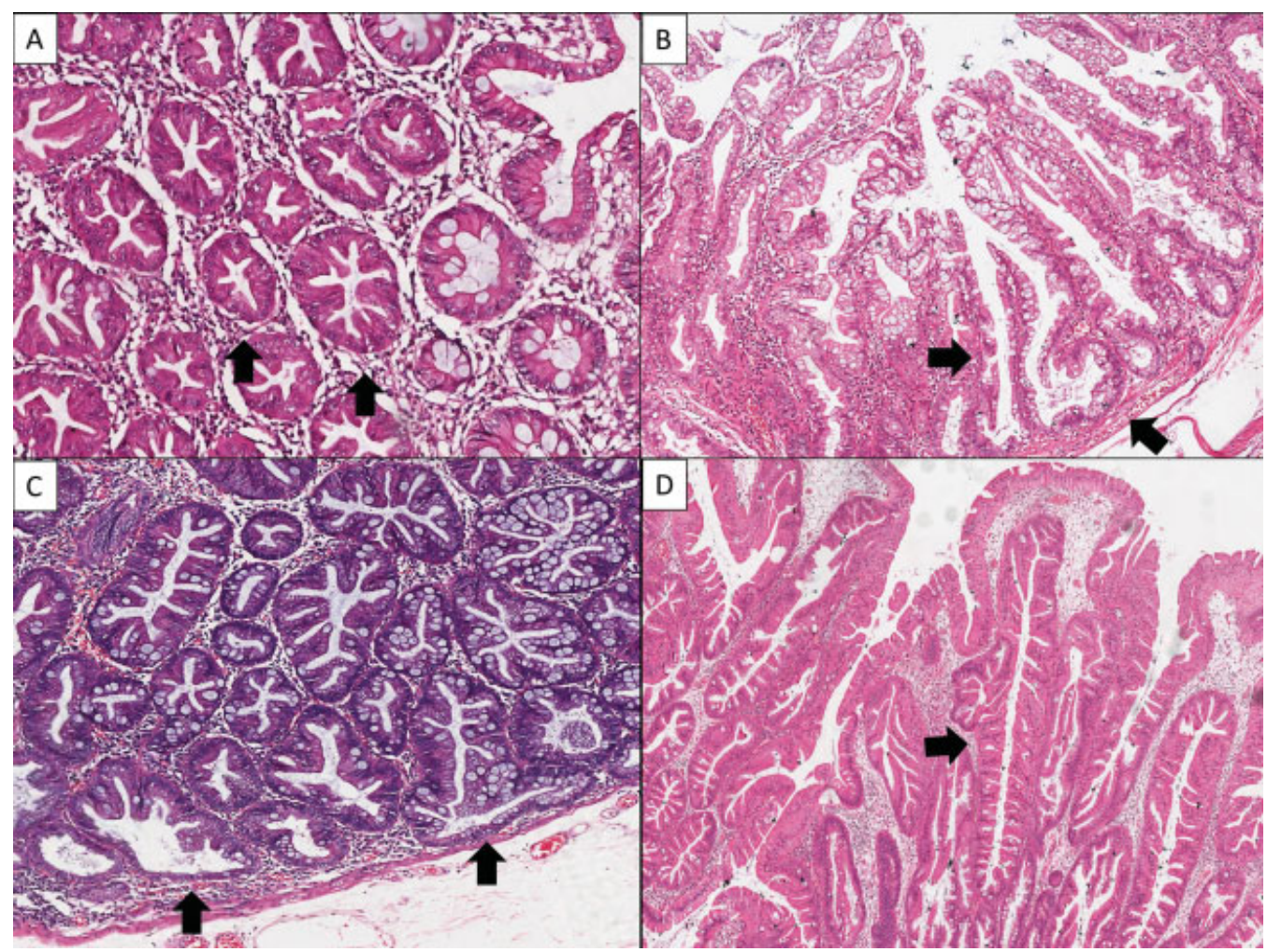

Fig. 1 (A) Hyperplastic polyp. Rounded glands with superficial and regular crypt serrations (arrows); (B) sessile serrated lesion with complete (including distal) crypt serration and characteristic lateral branching of the base of the crypt (arrows); (C) sessile serrated lesion with irregular (assymetric) crypt serration and lateral branching of the base of the crypt and dilatation (arrows); (D) traditional serrated adenoma, showing slitlike serration and eosinophilic cytoplasm. Staining method: Hematoxilin-Eosin. (Magnification: A and C - 200 X; B and D - 100 X).

alterations in only one crypt would be enough for the diagnosis. ${ }^{13}$ Divergences in established criteria may justify the difficulties to make an adequate diagnosis; it is estimated that $\sim 20 \%$ to $30 \%$ of lesions previously classified as HPs currently correspond to SSLs and TSAs, as observed in studies $^{4,8,15}$ on the reclassification of these lesions. The 2019 WHO classification ${ }^{9}$ considers a minimum criterion "the presence of at least one serrated crypt containing

Table 2 Serrated lesions and main and minor histological characteristics

\begin{tabular}{|c|c|c|}
\hline Serrated lesions & Main histological characteristics & Minor histological characteristics \\
\hline $\begin{array}{l}\text { Hyperplastic } \\
\text { polyps }\end{array}$ & $\begin{array}{l}\text { - Proliferative zone confined to crypt base. } \\
\text { - } \quad \text { Proximal crypt serration. } \\
\text { - } \text { More than one type of epitelial cell according to } \\
\text { the polyp type. }\end{array}$ & $\begin{array}{l}\text { - Localized basement membrane thickening. } \\
\text { - Individual crypt branching may eventually } \\
\text { - } \quad \text { Small. }\end{array}$ \\
\hline $\begin{array}{l}\text { Traditional } \\
\text { serrated adenoma }\end{array}$ & $\begin{array}{l}\text { - Eosinophilic cytoplasm and pencillate nuclei. } \\
\text { - } \text { Formation of ectopic crypt. } \\
\text { - } \text { Slit-like serration. }\end{array}$ & $\begin{array}{l}\text { - Flat-type traditional serrated adenoma may } \\
\text { show a few or no formation of ectopic crypts. } \\
\text { A few globet cells may be present, except in } \\
\text { the mucin-rich type, in which they are pre- } \\
\text { dominant. } \\
\text { - In up to } 50 \% \text { of the cases, a serrated pre- } \\
\text { cursor may be found. }\end{array}$ \\
\hline $\begin{array}{l}\text { Sessile serrated } \\
\text { lesions }\end{array}$ & $\begin{array}{l}\text { - } \text { Assymetric crypt dilation and/or branching. } \\
\text { - } \text { exteninal crypt serration throughout the entire } \\
\text { - Horizontal branching of the base of the crypt in } \\
\text { J, L or inverted-T pattern. } \\
\text { Crypt herniation through the muscularis } \\
\text { mucosa. }\end{array}$ & $\begin{array}{l}\text { - Microvesicular and globet cells. } \\
\text { - Proliferative zone in the middle and base of } \\
\text { the crypt. } \\
\text { - Most lesions do not exhibit epithelial } \\
\text { dysplasia. }\end{array}$ \\
\hline
\end{tabular}


unequivocal architectural distortions". Sessile serrated lesions may exhibit nuclear and cytoplasmic atypia similar to that of low- and high-grade dysplasia observed in CAs; in these situations, well-defined areas of cytological dysplasia are often identified in SSLs without dysplasia. These areas are almost always related to the loss of immunoexpression of MHL1 due to the inactivation of the gene, common in the MSI pathway, but unusual in the classic carcinogenesis scheme ${ }^{15}$; at the same time, foci of dysplasia retain the BRAF gene mutation observed in the remainder of the SSL. The identification of dysplasia is considered a marker of progression to CRC, associated with rapid increase in size. In addition, the focus of dysplasia in SSLs with malignant transformation is often identified, and identification of SSLs with cytological dysplasia in polyps of individuals without a history of CRC is infrequent. $^{13,15}$

More than one type of dysplasia is described in SSLs; however, the importance of differentiation and graduation is still an issue to be defined. The most common type, conventional dysplasia (similar to that of adenomas), is characterized by the presence of elongated cells with pseudostratified and hyperchromatic nuclei, amphophilic cytoplasm, and increased number of mitoses. Although graduation into low and high grades is performed in CAs, the importance of the graduation of SSL dysplasia is not clear, and the recommendation is to consider lesions with cytological dysplasia as a polyp of greater risk (advanced), with management similar to that of high grade adenomas. ${ }^{16}$ A second, less described type of dysplasia is the "serrated dysplasia," rarely observed in SSLs, characterized by the proliferation of more cuboidal atypical cells, with eosinophilic cytoplasm, increased nuclear size with vesicular chromatin and prominent nucleolus, as well as an increased number of mitoses; this pattern is considered by some authors a marker of tumor progression. $^{13}$

\section{Traditional Serrated Adenoma}

The third type of serrated polyp is the TSA, which usually exhibits a protuberant exophytic configuration, villous architectural pattern with rounded ends, coated by large numbers of columnar cells with eosinophilic cytoplasm, and elongated and pseudostratified nuclei. A usual characteristic is the presence of so-called "ectopic crypts," whose formation seems to be related to the loss of their normal anchorage to the muscularis mucosa. Both types of dysplasia can be found in TSAs; however, it is discussed whether the serrated pattern represents a real dysplastic alteration or a metaplastic one, since it differs from the cytological and architectural pattern of conventional dysplasia. The overall prevalence of this type of condition is of $0.6 \%{ }^{4,13}$ With neoplastic progression, TSAs are believed to have increased levels of cytological atypia prior to the development of carcinoma. There is no consensus regarding the identification or graduation of dysplasia in TSAs, and the recommendation is that should be graded similarly to CAs (low and high grades). A recent study ${ }^{8}$ showed that $25 \%$ of the TSAs studied had high-grade dysplasia, and $8 \%$ presented intramucous carcinomas. The risk of malignancy in TSAs and the time of progression are yet to be defined. ${ }^{13,17}$ The molecular profile described for TSAs exhibits great heterogeneity, which can be partially attributed to the confusing terminology and difficulty in diagnosing serrated lesions. ${ }^{15}$ The data available suggest that TSAs are not part of the serrated pathway, at least regarding SSLs, since they do not always present MLH1 hypermethylation and BRAF mutations, and may also exhibit KRAS and p53 mutations. Despite all these controversies, it is believed that they are better managed, in terms of follow-up and treatment, such as tubular adenomas of the same size. ${ }^{13}$

\section{Non-classifiable Serrated Adenoma}

This was a category introduced in the 2019 WHO classification, ${ }^{9}$ with the purpose of including serrated polyps of difficult distinction, especially TSAs and SSLs with dysplasia. The newly described serrated tubullo-villous adenoma (TVA) is also included in this group. ${ }^{9}$ Possibly, given the uncertainty regarding the characteristics of this group of lesions, the microscopic criteria for this category were not described in this edition.

\section{Reproducibility and Interobserver Agreement in the Histopathological Diagnosis of Serrated Lesions}

The detection of serrated lesions depends mainly on the examiner" experience; approximately half of the lesions in the proximal colon go unnoticed during the endoscopic examination, which contributes to the lower detection rates of proximal colon cancers compared with distal lesions. ${ }^{16}$ The surveillance and treatment of serrated lesions, within each histological type, diverge from those of conventional adenomas, based on the 2012 consensus recommendations of the American Society of Gastrointestinal Endoscopy (ASGE), the AGA, and the American College of Gastroenterology (ACG). In general, serrated lesions larger than $10 \mathrm{~mm}$ and/or presenting cytological dysplasia, as well as TSAs, have a surveillance periodicity of 3 years, lower than that of tubular adenomas with low-grade dysplasia. ${ }^{16}$ Despite the existing recommendations, the strategies for the surveillance of serrated lesions can only be adequately used after the proper histological diagnosis. However, the literature ${ }^{14,18-22}$ highlights a great difficulty related to the adoption and interpretation by the pathologists of the criteria for the classification of serrated lesions. Part of this difficulty is probably related to the different denominations applied, as well as to the subjectivity of the existing histological criteria. Moreover, each type of polyp has peculiarities, which lead to confusion between one or more histological types (not necessarily only with serrated polyps). The related studies addressing this issue consider two main points: the percentage of HP reclassifications to SSA, MP, SSA/P and TSA, and the IOC or intraobserver concordance based on the kappa coefficient, according to the classifications, denominations and criteria presented in the $2000^{12}$ and $2010^{3}$ WHO classifications (depending on the year of the paper). As an example, a study $^{20}$ conducted in 2014 shows that 41 (20.5\%) among 200 polyps (serrated and conventional) presented discordant diagnoses, and that the use of the $2010 \mathrm{WHO}^{3}$ classification, led to a reduction in the diagnosis of SSA/Ps and an increase 
in the detection of HPs, due to the adoption of more rigid criteria. Currently, with the change in diagnostic criteria for "only one crypt" containing the histological characteristics of SSLs, this will probably lead to new IOC profiles, even though there does not seem to be yet a published study on this topic.

One of the most cited studies was performed in $2007 .{ }^{22}$ In it, an online quiz was conducted with microphotographs of 20 lesions and 168 observers from different countries, for which 4 diagnoses were admitted (HP, TVA, SSA and TSA). The denominations most used by the participants were investigated, resulting in more than 19 different terms used, such as: serrated polyp with anomalous proliferation, traditional mixed serrated adenoma, sessile serrated adenoma, hyperplastic-adenomatous mixed polyp, among others. ${ }^{22}$ It also should be pointed out from this study that the mean agreement percentage was $\sim 48 \%$, with SSAs being more confused with HPs and TSAs, and TSAs more confused with TVAs. It is noteworthy that $9.4 \%$ of the participants claimed to have never used the term serrated adenoma as a diagnosis.

Another frequently cited study ${ }^{23}$ was conducted in 2009 , containing 40 HPs diagnosed in 2001 by pathologists with no experience in gastrointestinal-tract pathology (GITP). It was proposed that the cases were reviewed by 3 GITP specialists in 2007, based on the current knowledge of that time (probably aligned with the guidelines later published in 2010 by the $\mathrm{WHO}^{3}$ ). The authors demonstrated that $~ 30 \%$ to $85 \%$ of HPs were reclassified as SSAs, with a kappa coefficient of 0.16 (very poor or poor agreement).

In 2009 , a study ${ }^{18}$ described a general agreement of $42 \%$ and a kappa coefficient of 0.49 (moderate) for all types of polyps, and 0.38 (fair) for SSAs and 0.53 (moderate) for HPs. However, this study does not distinguished between TSAs and SSA/Ps. Compared with this study, another one from $2008^{21}$ presented an almost perfect IOC (kappa coefficient $>0.80$ ) for the diagnosis of TSAs; however, it did not include in its case series CAs or MPs, which probably reduced the possibility of disagreement among observers; the kappa values were also obtained for the other categories, which ranged from 0.45 to 0.47 for SSAs; from 0.42 to 0.52 for HPs; and from 0.46 to 0.58 for all lesions in general (moderate agreement).

In 2013, 2 studies ${ }^{24,25}$ described the review and reclassification of cases previously diagnosed as HPs in the right colon from 2009 to 2012, using, however, the criteria of the AGA, ${ }^{13}$ (minimum of 1 crypt containing the characteristic histological changes), currently adopted in the 2019 WHO classification. $^{3}$ The studies found a percentage reclassification range, in each year, of $30 \%$ to $64 \%$ of cases (average of $42 \%$ over the 4 years), mainly for the diagnosis of SSA/Ps; as an example, in 2009, there was no record of diagnosis of any SSA/P, and 66 HPs in the right colon. Of these, $30 \%$ of the cases were reclassified as SSA/Ps, and $1 \%$, as TSAs. The percentage of reclassification of SSA/Ps observed was of up to $5 \%$ of the cases, suggesting that the greatest difficulty lied in the differentiation of HPs from SSLs, not the contrary. The kappa value was not calculated in these studies. ${ }^{24,25}$

Two other studies ${ }^{19,20}$ show important data on this topic: the first of them, from $2014,{ }^{20}$ evaluated 200 lesions with diagnoses of CA, SSA, HP and MP. The general IOC was moderate to good (kappa: 0.56 and 0.68 ), but the agreement in the use of cytological and architectural criteria for diagnosis was analyzed, with large variations and low levels, especially between the SSA and TSA criteria, such as crypt inversion (kappa: 0.25) and crypt dilation (kappa: 0.38), formation of ectopic crypts (kappa: 0.25 ) and eosinophilic cytoplasm (kappa: 0.06). Variations in diagnosis were also calculated in different scenarios: A (before the disclosure of the diagnostic criteria), B (after the disclosure of age, gender and location of the lesion) and $C$ (after the disclosure of the consensus on criteria). The greatest change observed in the diagnosis of SSAs and HPs occurred mainly in scenario C, associated with greater difficulty in the application of semiquantitative criteria, situations that had already been addressed in another study, ${ }^{24}$ in which the use of criteria such as one or two crypts for the diagnosis seem to lead to significant changes in the trend of one or another diagnosis. Another study, ${ }^{19}$ performed in 2012 with 70 cases and conducted in two stages, one before the consensus discussion and another after the definition of criteria based on the 2010 WHO classification, ${ }^{3}$ showed an agreement of 0.318 and 0.557 (fair to moderate) for each stage respectively. It is noteworthy that, after the definition of criteria, the agreement regarding the diagnosis of HPs, SSLs and TSAs increased from $0.415,0.301$ and 0.433 to $0.977,0.912$ and 0.845 respectively; the global kappa coefficient, however, remained 0.557 , possibly due to the very poor agreement regarding MPs (0.158), which even decreased after the disclosure of the criteria. Moreover, it is important to say that there were no cases of CA in this study, ${ }^{19}$ which could possibly reduce the chance of misdiagnosis with MPs and serrated adenomas with dysplasia (in this study considered equivalent to SSL with dysplasia). This study ${ }^{19}$ also evaluated the concordance between histological criteria, similarly to the previously mentioned 2014 study, ${ }^{20}$ in which serrated superficial crypts (kappa coefficient: 0.97), serrated superficial epithelium (0.83), mitoses in the basal portion (0.79), goblet cells in the superficial crypts (0.77), and dilation in the superficial portion of the crypts $(0.72)$ showed higher levels of agreement. The criteria with better discrimination capacity for each diagnostic category were: serration, dilatation and goblet cells in the superficial crypts in HP; horizontal dilatation of basal crypts and vesicular nuclei with nucleoli in SSA; and formation of ectopic crypts, cytoplasmic eosinophilia, pseudostratification, hyperchromasia, and nuclear elongation in TSA. Thus, it is suggested that architectural criteria present greater discriminatory capacity for HP and SSA, and cytological criteria contribute more to the diagnosis of TSA.

Finally, a 2015 study $^{26}$ showed 27 HPs reclassified as SSAs (SSLs and TSAs) among 310 polyps studied, resulting in a total of 31 SSAs, from 3 SSAs initially identified, and a kappa coefficient of 0.102 (very poor agreement). Over the years, other studies ${ }^{27,28}$ have shown similar results. - Table 3 summarizes the main studies on the subject in the literature.

Considering all of these studies, it was possible to observe that those including lesions other than serrated ones, such as 
Table 3 Interobserver variability in different series

\begin{tabular}{|c|c|c|}
\hline Authors & Number of cases & Interobserver concordance \\
\hline $\begin{array}{l}\text { Baldin et al., } 2015 \\
\text { Rau et al., } 20142014\end{array}$ & $\begin{array}{l}n=310(\mathrm{HP} / \mathrm{SSA} / \mathrm{CA}) \\
n=200(\mathrm{HP} / \mathrm{SSA} / \mathrm{TSA} / \mathrm{MP} / \mathrm{CA} / \mathrm{OL})\end{array}$ & $\begin{array}{l}\text { Very poor } \\
\text { Fair to good }\end{array}$ \\
\hline Gill et al., ${ }^{24} 2013$ & $n=797(\mathrm{HP} / \mathrm{SSA})$ & $\begin{array}{l}30 \% \text { to } 64 \% \text { of HPs reclassified as SSAs, over } 4 \text { years } \\
\text { (kappa not calculated) }\end{array}$ \\
\hline Ensari et al., ${ }^{19} 2012$ & $n=70(\mathrm{HP} / \mathrm{SSA} / \mathrm{TSA} / \mathrm{MP})$ & $\begin{array}{l}\text { Good (in general) and very good for HP, SSA } \\
\text { and TSA }\end{array}$ \\
\hline Gunia et al., ${ }^{27} 2011$ & $n=19(\mathrm{SSA} / \mathrm{TSA} / \mathrm{IP})$ & Poor to fair \\
\hline Bustamante-Balén et al., ${ }^{28} 2009$ & $n=195(\mathrm{HP} / \mathrm{SSA})$ & Very poor \\
\hline Wong et al., ${ }^{18} 2009$ & $n=60(\mathrm{HP} / \mathrm{SSA} / \mathrm{MP} / \mathrm{CA} / \mathrm{OL})$ & Poor \\
\hline Khalid et al., ${ }^{23} 2009$ & $n=40(\mathrm{HP} / \mathrm{SSA})$ & Very poor \\
\hline Farris et al., 212008 & $n=185(\mathrm{HP} / \mathrm{SSA} / \mathrm{TSA})$ & Good \\
\hline
\end{tabular}

CA, conventional adenoma; HP, hyperplastic polyp; IP, inflammatory polyp; MP, mixed polyp; OL, other lesions; SSA, sessile serrated adenoma; TSA, traditional serrated adenoma.

CAs, and lesions of other nature (inflammatory, reactive or normal mucosa lesions), showed higher levels of reclassification and lower IOC. This data suggests that when the study included a lower variety of lesions or restricted evaluation criteria, the chances of discordances in the evaluation were reduced. For example, CAs usually do not pose great diagnostic difficulty regarding HPs and SSLs; however, they can be easylly mistaken for TSAs, which are rare lesions with a frequency $\sim$ $1 \%, 22,24,25$ whose difficulty to diagnose may not be clear if there is not a representative number of TSAs in the study.

A condition little addressed in reclassification studies of serrated polyps, but frequent in the pathologist routine, is the difficulty that sometimes exists to differentiate an HP from a reactive lesion. A possible explanation might be the presence of microscopic features of crypt hyperplasia and polypoid aspect observed in colonoscopies, in reactional or inflammatory lesions, acting as a confounding factor. Another possibility that could justify it, is the lack of recognition of the neoplastic potential of HPs by pathologists, as a lesion of the serrated carcinogenesis pathway, who might tend to opt for this diagnosis at the time of evaluation of a suspected lesion (both on colonoscopy and microscopic analysis) in case of doubt, since they may consider it as an innocuous or without carcinogenic potential.

Finally, the great variation in the rates of diagnostic agreement for SSLs and TSAs reflects the magnitude of the problem regarding the diagnosis of these lesions, which end up being confused with each other and with other colorectal polyps. Regarding HPs, it is recognized that they are the main simulators of SSLs, and that, in the past, most SSLs were diagnosed as HPs or MPs. ${ }^{20,21,23,24}$ Although there are not many reports in the literature about the diagnostic difficulty in differentiating between CAs with SSLs and HPs, it is worth mentioning the perception by the pathologists that SSLs and TSAs are lesions with dysplasia, probably due to previous denominations as serrated adenomas and mixed polyps, when in fact the presence of dysplasia in these lesions is not so frequent, corresponding only to $\sim 5 \%$ of cases of SSL, for example. ${ }^{21}$ Moreover, the presence of hyperplastic chan- ges in the crypts of conventional adenomas is not infrequent, often leading the pathologist to resort to the old term "hyperplastic-adenomatous mixed polyp". This term, which was no longer used since the 2010 WHO classification ${ }^{3}$ as a specific type of serrated lesion, apparently came to be considered again in the new classification, ${ }^{9}$ under the term non-classified serrated polyp, whose frequency and minimum microscopic criteria have not yet been defined.

\section{Conclusions}

The recognition of the role of serrated lesions in colorectal carcinogenesis and its implications in the screening, followup and treatment of these lesions are limited, due to the current difficulty in defining and reproducing the main microscopic diagnostic criteria. ${ }^{29,30}$ Besides that, the multiple terms applied in recent decades, sometimes confusing, compromise the evaluation of the diagnostic reproducibility and IOC. Although the first descriptions of this condition date from 1990, in the last 3 WHO classifications, ${ }^{3,9,12}$ the described levels of diagnostic disagreement still range from $30 \%$ to $80 \%$, according to the main studies. This is an alarming fact that reflects the need to investigate within each institution the percentages of agreement, as well as the need to seek ways to standardize criteria and reduce subjectivity, aiming at better diagnostic quality. Despite all the advances in the knowledge of the molecular biology and carcinogenesis pathways of these lesions, there is no consensus on the use of one or more markers (immunohistochemical or molecular) that could play a defining role in the diagnosis of this condition. Studies ${ }^{8,9}$ with antibodies not used in the daily routine of immunohistochemistry, such as BRAF and Anexin A10, as well as molecular methods not often available (such as, methylation assays), still require further investigation. It is also essential to investigate diagnostic tools that can evaluate which of the microscopic criteria already described show better performance in the diagnosis, as well as greater reproducibility, to play a decisive role in diagnostic conclusion. 


\section{Conflict of Interests}

The authors have no conflict of interests to declare.

\section{References}

1 Bowel Cancer. 2020. Available at: [accessed: 02.04.2020, online]. https://www.inca.gov.br/tipos-de-cancer/cancer-de-intestino

2 Yamane L, Scapulatempo-Neto C, Reis RM, Guimarães DP. Serrated pathway in colorectal carcinogenesis. World J Gastroenterol 2014;20(10):2634-2640

3 Snover DC, Ahnen Dj, Burt RW, et al. Serrated polyps of the colon and rectum and serrated polyposis. In: Bosman FT, Carneiro F, Hruban RH, Theise ND. World Health Organization Classification of Tumours of the Digestive System. 4th ed. Lyon: IARC Press; 2010:160-171

4 Bordaçahar B, Barret M, Terris B, et al. Sessile serrated adenoma: from identification to resection. Dig Liver Dis 2015;47(02): 95-102

5 East JE, Atkin WS, Bateman AC, et al. British Society of Gastroenterology position statement on serrated polyps in the colon and rectum. Gut 2017;66(07):1181-1196

6 Longacre TA, Fenoglio-Preiser CM. Mixed hyperplastic adenomatous polyps/serrated adenomas. A distinct form of colorectal neoplasia. Am J Surg Pathol 1990;14(06):524-537

7 Torlakovic E, Snover DC. Serrated adenomatous polyposis in humans. Gastroenterology 1996;110(03):748-755

$8 \mathrm{Kim}$ KM, Lee EJ, Ha S, et al. Molecular features of colorectal hyperplastic polyps and sessile serrated adenoma/polyps from Korea. Am J Surg Pathol 2011;35(09):1274-1286

9 Father RK, Mäkinen MJ, Rosty C. Colorectal serrated lesion and polyps. In: World Health Organization Classification. Digestive System Tumours 5th ed. Lyon: IARC Press; 2019:163-174

10 Fu B, Yachida S, Morgan R, Zhong Y, Montgomery EA, IacobuzioDonahue CA. Clinicopathologic and genetic characterization of traditional serrated adenomas of the colon. Am J Clin Pathol 2012; 138(03):356-366

11 Vatn $\mathrm{MH}$, Stalsberg $\mathrm{H}$. The prevalence of polyps of the large intestine in Oslo: an autopsy study. Cancer 1982;49(04): 819-825

12 Hamilton SR, Vogelstein B, Kudo S, et al. In: Hamilton SR, Aaltonen LA. World Health Organization Classification of Tumours. Pathology and Genetics of Tumours of the Digestive System 3rd ed. Lyon: IARC Press; 2000:113-114

13 Rex DK, Ahnen DJ, Baron JA, et al. Serrated lesions of the colorectum: review and recommendations from an expert panel. Am J Gastroenterol 2012;107(09):1315-1329, quiz 1314, 1330

14 Bateman AC, Shepherd NA. UK guidance for the pathological reporting of serrated lesions of the colorectum. J Clin Pathol 2015;68(08):585-591

15 Batts KP. The pathology of serrated colorectal neoplasia: practical answers for common questions. Mod Pathol 2015;28(Suppl 1): S80-S87
16 Sweetser S, Smyrk TC, Sinicrope FA. Serrated colon polyps as precursors to colorectal cancer. Clin Gastroenterol Hepatol 2013; 11(07):760-767, quiz e54-e55

17 Rosty C, Hewett DG, Brown IS, Leggett BA, Whitehall VLJ. Serrated polyps of the large intestine: current understanding of diagnosis, pathogenesis, and clinical management. J Gastroenterol 2013;48 (03):287-302

18 Wong NA, Hunt LP, Novelli MR, Shepherd NA, Warren BF. Observer agreement in the diagnosis of serrated polyps of the large bowel. Histopathology 2009;55(01):63-66

19 Ensari A, Bilezikçi B, Carneiro F, et al. Serrated polyps of the colon: how reproducible is their classification? Virchows Arch 2012;461 (05):495-504

20 Rau TT, Agaimy A, Gehoff A, et al. Defined morphological criteria allow reliable diagnosis of colorectal serrated polyps and predict polyp genetics. Virchows Arch 2014;464(06):663-672

21 Farris AB, Misdraji J, Srivastava A, et al. Sessile serrated adenoma: challenging discrimination from other serrated colonic polyps. Am J Surg Pathol 2008;32(01):30-35

22 Glatz K, Pritt B, Glatz D, Hartmann A, O’Brien MJ, Blaszyk H. A multinational, internet-based assessment of observer variability in the diagnosis of serrated colorectal polyps. Am J Clin Pathol 2007;127(06):938-945

23 Khalid O, Radaideh S, Cummings OW, O’Brien MJ, Goldblum JR, Rex DK. Reinterpretation of histology of proximal colon polyps called hyperplastic in 2001. World J Gastroenterol 2009;15(30):3767-3770

24 Gill P, Wang LM, Bailey A, East JE, Leedham S, Chetty R. Reporting trends of right-sided hyperplastic and sessile serrated polyps in a large teaching hospital over a 4-year period (2009-2012). J Clin Pathol 2013;66(08):655-658

25 Gill P, Rafferty H, Munday D, et al. Proximal colon cancer and serrated adenomas - hunting the missing $10 \%$. Clin Med (Lond) 2013;13(06):557-561

26 Baldin RKS, Anselmi RA Jr, Azevedo M, et al. Interobserver variability in histological diagnosis of serrated colorectal polyps. J Coloproctol (Rio J) 2015;35(04):193-197

27 Gunia S, Berg T, Gradhand E, Becker S. Knowledge of the anatomical polyp location might bias the pathological classification of histologically equivocal colorectal serrated polyps - a consensus study performed by pathology trainees. Pathol Res Pract 2011; 207(02):116-120

28 M Bustamante-Balén Bernet L, Cano R, Morell L, López A. Assessing the reproducibility of the microscopic diagnosis of sessile serrated adenoma of the colon. Rev Esp Enferm Dig 2009;101(04):258-264

29 Rex DK, Boland CR, Dominitz JA, et al. Colorectal Cancer Screening: Recommendations for Physicians and Patients from the U.S. Multi-Society Task Force on Colorectal Cancer. Am J Gastroenterol 2017;112(07):1016-1030

30 Lieberman DA, Rex DK, Winawer SJ, Giardiello FM, Johnson DA, Levin TR. Guidelines for colonoscopy surveillance after screening and polypectomy: a consensus update by the US Multi-Society Task Force on Colorectal Cancer. Gastroenterology 2012;143(03): 844-857 